\title{
UNA PRESENCIA DE ANTOLOGÍA. LA TRADUCCIÓN AL ESPAÑOL DE LA POESÍA DE KATHLEEN RAINE ${ }^{1}$
}

\author{
AN ANTHOLOGICAL PRESENCE. THE TRANSLATION OF KATHLEEN RAINE'S \\ POETRY INTO SPANISH
}

\author{
UMA PRESENÇA ANTOLÓGICA. A TRADUÇÃO DA POESIA DE KATHLEEN \\ RAINE PARA O ESPANHOL
}

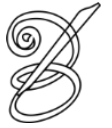 \\ María Laura SPOTURNO² \\ Consejo Nacional de Investigaciones Científicas y Técnicas, Argentina \\ Universidad de la Plata, Argentina.
}

\begin{abstract}
Resumen: Este artículo tiene dos objetivos principales. Luego de revisar algunos de los problemas que caracterizan la traducción de poesía, se reseña, en primer lugar, la presencia poética de Kathleen Raine (19082003) en el ámbito de la traducción en español. En segundo lugar, sobre la base de un caso de estudio singular, se identifican las particularidades y desafíos que plantea la traducción de la poesía de Raine al español. En las letras hispanas, la voz poética de Raine se ve atravesada y constituida por una existencia de antología, lo cual le confiere un carácter necesariamente fragmentario, incompleto en su decir. Más aún, la fragmentariedad que implica toda antología se ve reflejada en las estrategias y técnicas que se ponen en juego en la traducción. A fin de corroborar nuestra hipótesis, el caso de estudio, constituido por la colección poética The Presence (RAINE, 1987), se centra en el examen pormenorizado de la traducción del poema "The Presence" al español, incluido en la antología Fragmentos de una visión sagrada (RAINE [Trad.: Alzueta Jesús], 2006). La consideración de la versión del poema en francés, incluida en la colección La Présence (RAINE [Trad.: Giraudon], 2003), ofrece un contrapunto de interés para ponderar las posibilidades expresivas de la traducción en el seno de dos lenguas romances. El análisis efectuado busca poner de relieve los procedimientos a través de los cuales se materializa el estilo distintivo de Raine y las técnicas desarrolladas para su recreación en el seno de la traducción.
\end{abstract}

Palabras clave: Traducción de poesía. Kathleen Raine. The Presence. Antologías (de traductor).

Abstract: This paper has two main goals. After presenting some of the problems that characterize poetry translation, it reviews the poetic presence of Kathleen Raine (1908-2003) in Spanish translation. Secondly, on the basis of a case study, the analysis seeks to identify the particular characteristics and challenges posed by the translation of Raine's poetry into Spanish. Within Spanish letters, the poetic voice of Raine is signaled and constituted by an anthological existence, which necessarily endows it with a fragmentary, incomplete character. Moreover, the fragmentariness implied in every anthology is reflected in the translation strategies and techniques at stake in translation. To test our hypothesis, the case study, constituted by the poetic collection The Presence (RAINE, 1987), centers on the detailed examination of the Spanish translation of the poem "The Presence", included in the anthology Fragmentos de una visión sagrada (RAINE [Transl.: Alzueta Jesús], 2006). The consideration of the French version of the poem, included in the collection La Présence (RAINE [Transl.: Giraudon], 2003), makes an interesting counterpoint to assess the expressive possibilities of translation within two Romance languages. This analysis highlights the procedures used to materialize Raine's distinctive style and the techniques developed to recreate such style in translation.

Keywords: Poetry Translation. Kathleen Raine. The Presence. (Translator's) Anthologies.

Resumo: Este artigo tem dois objetivos principais. Depois de rever alguns dos problemas que caracterizam a tradução da poesia, se estuda, em primeiro lugar, a presença poética de Kathleen Raine (1908-2003) no campo da tradução em espanhol. Finalmente, com base em um estudo de caso singular, identificamos as particularidades 
e desafios colocados pela tradução da poesia de Raine para o espanhol. Nas letras hispânicas, a voz poética de Raine é atravessada e constituída por uma existência de antologia, que confere caráter necessariamente fragmentário, incompleto. Além disso, a fragmentação que toda antologia implica está refletida nas estratégias e técnicas que são postas em jogo na tradução. Para corroborar nossa hipótese, o estudo de caso, que consiste na coleção de poesia The Presence (RAINE, 1987), centra-se na análise detalhada da tradução do poema "The Presence" em espanhol, incluída na antologia Fragmentos de una visión sagrada (RAINE [Trad.: Alzueta Jesús], 2006). Consideração da versão francesa do poema, incluído na coleção La Présence (RAINE [Trad.: Giraudon], 2003), oferece um contraponto de interesse para refletir sobre as possibilidades expressivas da tradução em duas línguas românicas. A análise efetuada procura evidenciar os procedimentos através dos quais se materializa o estilo distintivo de Raine e as técnicas desenvolvidas para a sua recriação dentro da tradução.

Palavras-chave: Tradução de poesia. Kathleen Raine. The Presence. Antologias (do tradutor).

RECEBIDO EM: 28 de julho de 2018

ACEITO EM: 26 de outubro de 2018

PUBLICADO EM: abril 2019 


\section{Introducción}

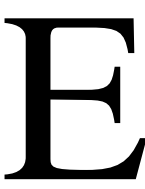

$\mathrm{n}$ este trabajo, nos proponemos dos objetivos principales. En primer término, se busca reseñar la presencia poética de la prestigiosa autora británica Kathleen Raine (19082003) en el ámbito de las letras hispanas. En segundo término y de modo complementario, se identifican las particularidades y desafíos que plantea la traducción de la obra poética de esta autora al español. Como veremos, la voz poética de Raine en español aparece atravesada y constituida por una existencia que se circunscribe al ámbito de las antologías. Esta condición aporta, según entendemos, un carácter necesariamente fragmentario e incompleto a su decir. En efecto, al escoger fragmentos de la obra de un poeta, entre la de otros poetas e incluso entre la propia producción de un mismo poeta, los antólogos destacan ciertas cualidades que se corresponden con una visión poética y un proyecto creativo determinados, los cuales no necesariamente coincidirán con los del poeta. Al igual que el resto de los géneros literarios, las antologías están sujetas, como indica Barbara Benedict (2003), a las condiciones históricas y culturales de producción y recepción en las que se insertan. Según esta autora, las antologías ponen de relieve la singularidad y la autonomía de sus partes, pero al mismo tiempo, afirman la semejanza que aglutina esas partes como un todo, recompuesto y recontextualizado. La traducción de antologías y selecciones, en la que muchas veces interviene el antólogo, implica nuevos procesos de selección, el desarrollo de una nueva agenda y las relaciones que se establecen con nuevos contextos de producción y recepción. Aquí, cabe recordar la distinción entre antologías de editor y antologías de traductor para la dinámica del campo literario (FRANK, 1998). Mientras que las primeras se presentan como una exhibición de textos ya existentes en una lengua determinada, las segundas actúan también como vehículo de transferencia. Tal como se advertirá, la fragmentariedad que implica toda antología se ve reflejada en las estrategias y técnicas que se ponen en juego en la traducción.

Para el análisis, partiremos del estudio de la colección poética The Presence, publicada por Raine en 1987 con el aval de Golgonooza Press, y nos detendremos especialmente en el análisis de un poema: "The Presence”. El examen de la traducción de ese poema al español, que ha sido incluida en la antología española Fragmentos de una visión sagrada (RAINE [Trad. de E. Alzueta Jesús], 2006), se enriquecerá con la consideración de la versión del poema en francés, sita en la colección La Présence (RAINE [Trad. de P. Giraudon], 2003). El caso del francés nos servirá como contrapunto para ponderar las posibilidades expresivas de la traducción en el ámbito de dos lenguas romances, las cuales, y no obstante sus rasgos comunes, ofrecen una búsqueda de la significación de la palabra poética desigual ${ }^{3}$. El examen 
pormenorizado de un poema particular y de sus traducciones busca poner de relieve los procedimientos a través de los cuales se materializa el bello y despojado estilo de Raine y las técnicas desarrolladas para su recreación en el seno de la traducción ${ }^{4}$.

Hemos organizado este artículo de la siguiente manera. En la sección siguiente, se caracteriza de manera sucinta la singularidad de la enunciación poética y se individualizan algunos de los problemas que conlleva la traducción de poesía. La tercera sección ofrece una reseña de las distintas traducciones de la obra poética de Raine al español. La cuarta presenta el análisis comparado de dos traducciones del poema seleccionado. Finalmente, en la quinta y última sección, se exponen las conclusiones a las que arribamos a partir de este estudio.

\section{Enunciación poética y traducción}

La traducción de poesía o traducción poética ha ocupado tradicionalmente una buena parte de las reflexiones en el ámbito de la traductología. Sin dudas, al indagar la traducción de un poema particular, se reanima la inquietud sobre la posibilidad misma de esa traducción (HOLMES, 1994; JAKOBSON, [1959] 1981; HONING, 1985; BOASE-BEIER, 2009, 2013).

110 Dirimida entre la doble conciencia de imposibilidad y posibilidad (CLARO, 2012), la traducción de poesía nos compele a una lucha incitante con la palabra y el sentido, en la que se pone en juego la búsqueda de las características, siempre imprecisas, que podrían, acaso, definir la naturaleza de la poesía o de lo que a veces, a falta de un mejor nombre, llamamos estilo poético. Con una motivación eminentemente pedagógica, entre los rasgos de ese estilo, generalmente se señalan los siguientes: (a) La disposición física, pues la forma que adopta el poema en el espacio resulta significativa en términos de su sentido. El sentido, a menudo, se articula a través de los quiebres sintácticos habilitados por la organización en versos (BOASEBEIER, 2013). (b) El empleo de una lengua inventiva, el cual muchas veces se relaciona con diversos patrones acústicos y estructurales (EAGLETON, 2007). (c) La polisemia intrínseca de la materia poética; es decir, la indeterminación del sentido que acompaña su enunciación (FURNISS; BATH, 2007). (d) La naturaleza no pragmática del discurso poético, la cual exige un tipo de lectura particular (HIRSCH, 1999; WOLOSKY, 2000; EAGLETON, 2007; FURNISS; BATH, 2007; FOSTER, 2018, entre otros).

Una vez superado el debate en torno a su traducibilidad, los estudios sobre traducción de poesía se han detenido, entre otros aspectos, en el examen de la reconstrucción del estilo poético, la transposición del yo lírico en la traducción y también en el estatus que se le confiere al poema traducido, tanto en lo que respecta a su producción como a su recepción dentro de un 
campo literario determinado (JAKOBSON, [1959] 1981; HONING, 1985; BOASE-BEIER, 2009, 2011; VENUTI, 2011; CLARO, 2012; MUSCHIETTI, 2013, entre muchos otros). Con respecto a su estatus, Don Paterson (2006), por ejemplo, distingue dos posibles alternativas: la primera, que denomina traducción, implica, según su propio decir, fidelidad a la palabra, a las relaciones que se articulan en el poema fuente y a la reposición de la elegancia de su estilo en el texto meta; la segunda, llamada versión, supone la presentación del poema traducido como poema de la cultura receptora. Autores como Lawrence Venuti (2011) entienden que, al abordar el estudio de la traducción de un poema, el punto central reside en dirimir si esa traducción confirma o desafía prácticas y saberes institucionalizados en la cultura receptora. Así, los condicionamientos que afectan la producción de una traducción deben cotejarse con aquellos que distinguen el espacio en el que esta ha de circular.

El estudio comparativo de las distintas versiones de un poema, uno de nuestros objetivos aquí, nos invita a explorar, como propone Lawrence Venuti (2011), la reinscripción del sentido que se revela en cada traducción particular en relación con una praxis determinada. No se trata, pues, de la búsqueda o la afirmación de la existencia de un invariante semántico, que la traducción debería reproducir, sino de elucidar cómo se transpone, percibe y circula el sentido poético en distintos contextos lingüísticos, literarios y culturales. Como indica el autor, el sentido se inscribe en la traducción en distintos niveles del proceso de escritura. Estos niveles comprenden desde la selección del texto que se traduce hasta la más mínima elección verbal en el poema traducido. De este modo, el análisis de la traducción de un poema nos invita a reflexionar sobre la reorganización de la palabra poética en tres planos diferentes, los cuales definen el proceso de significación del poema: el plano intratextual, que distingue los procedimientos enunciativo-discursivos del texto fuente; el intertextual e interdiscursivo, que implica las múltiples y diversas relaciones entre textos y discursos; y, finalmente, el tercer plano, que se define como intertextual, interdiscursivo e intersemiótico, en tanto incluye los distintos medios y circuitos que componen los canales de difusión y recepción.

Conceptualizada como una ceremonia del verbo, un soplo inefable ${ }^{5}$, la poesía desarrolla su propia economía del decir. En su interior, "el sentido de una palabra no es lo que vale, sino su ambiente, su connotación, su ademán” (BORGES [1926], 1997, p. 256). La traducción poética arbitra la economía del sentido de esas palabras que quieren ser conjuro en nuevos espacios lingüísticos, culturales, literarios y también comerciales. Destinada, como solía decir Jorge Luis Borges, a ilustrar la discusión estética, la traducción poética convoca ciertamente a la búsqueda de la verdad poética en otra lengua. 


\section{La poesía de Kathleen Raine (en español)}

Raine es una de las poetas y críticas más destacadas de Gran Bretaña del siglo XX, cuya obra, sin embargo, no ha recibido aún un justo reconocimiento (KEEBLE, 2016). La labor poética de Raine se distingue, como apunta Rudman (2002), por el compromiso de vincular el intelecto y la emoción, así como por una perspectiva de la naturaleza, la creación y la creatividad que la ubica en el lugar de los visionarios. Sin dudas, pesa en ella una visión poética que se impone sobre todo lo demás (MONTEZANTI, 2013). Su obra crítica, ensayística y poética surge de una búsqueda interior urgente que reacciona frente a las ideologías materialistas imperantes en el siglo XX (LINDOP, 2006; KEEBLE, 2016). Formada en el ámbito de la ciencia, era estudiante en el Girton College de Cambridge cuando Virginia Woolf dictó la célebre conferencia que daría lugar al ensayo A Room of One's Own. Las aseveraciones de Woolf respecto de la relación entre la (posibilidad de la) escritura, el género y la clase agitaron su ya inquieto espíritu, en un ámbito académico que resultaba hostil a sus intuiciones más agudas respecto de la creación divina y de la imaginación (RAINE, 1995; KEEBLE, 2016).

La fina poesía de Raine aspira, como nos recuerda Montezanti (2017), a la belleza, al 112 espacio de lo elevado, lo sublime, lo inmutable ${ }^{6}$. Desprovista de tecnicismos y adornos superfluos, la obra poética de Raine, originada siempre en la visión imaginativa más profunda, dificulta su paráfrasis, como indica Keeble (2016), y su traducción, como apunta Montezanti (2017). Tal vez por eso sea que la presencia de la obra de Raine resulta bastante ocasional en el ámbito hispanohablante. La voz poética de Raine resuena en la labor de siete traductores principalmente. Motivados de manera diversa, en casi todos los casos, son los traductores quienes han seleccionado algunos pasajes de la obra de Raine para incluirlos en antologías y selecciones poéticas en revistas especializadas. Como queda anticipado, se trata de medios de producción y circulación que acentúan aún más la reducción, la exclusión y la reinscripción discursiva, literaria e institucional que, por su naturaleza, implica toda traducción (VENUTI, 2011).

La primera aparición de Raine en español la debemos a Marià Manent, quien publicó en 1951 la colección Poemas con el aval de Ediciones Rialp. Asimismo, Manent tradujo dos poemas de la autora, "For posterity" y "Winter fire", los cuales fueron incluidos en la prestigiosa Antología de poetas ingleses modernos, publicada por Gredos (ALONSO, 1963). Unos años más tarde, en 1981, el afamado sello editorial Hiperión publicó una edición bilingüe de On a Deserted Shore de 1973, con el título de En una desierta orilla. La traducción de este poemario, realizada por el renombrado escritor, crítico y traductor Rafael Martínez Nadal 
(1903-2001), tuvo una buena acogida en España, especialmente en círculos cultos y versados en poesía española. Debe destacarse que esta es la única obra de Raine en español que recoge un poemario completo. En 1991, se publicaron dos poemas de Raine traducidos en un apartado de la revista El Ciervo. Esa edición reunía un conjunto de voces femeninas occidentales que, a juicio de la editora y traductora Biruté Ciplijauskaité, resultaba testimonio de la creación de las mujeres y de su fe en la palabra poética. Asimismo, parte de la obra poética de Raine fue vertida al español por un grupo selecto de traductores, que incluye las voces de Marià Manent, Clara Janés y Rafael Martínez Nadal, como parte de una antología poética publicada en la revista Dáctilo en 1999. Asimismo, y a propósito de su fallecimiento, Clara Janés publicó una selección de poemas de Raine en la revista Adamar (2000-2004) acompañada de una introducción.

Más recientemente, en 2006, la Editorial Aljamía de Granada avaló la publicación de la traducción de una selección de poemas de Raine, Fragmentos de una visión sagrada, realizada por Emilio Alzueta Jesús, la cual es objeto de estudio aquí. En el año 2008, Ediciones Tres Fronteras de Murcia publicó la selección bilingüe de poemas Poesía y naturaleza, con prólogo y traducción de Adolfo Gómez Tomé. En 2017, de la mano del traductor e investigador Miguel Ángel Montezanti, la revista argentina Hablar de poesía le dedicó un espacio destacado a una selección de poemas de Raine, que fueron presentados en versión bilingüe e introducidos por comentarios críticos a cargo del traductor. Cada una de estas traducciones supone una interpretación selectiva de la obra de Raine y una consecuente reinscripción del sentido que no puede ser sino dispar. No obstante, en la mayoría de sus manifestaciones en español, la figura de Raine, que se distingue como una de las poetas fundamentales del siglo XX, concita la atención casi exclusivamente en círculos de recepción especializados y, particularmente, en ámbitos de lectores versados en poesía.

\section{En aras de la eficacia poética}

El poema seleccionado, “The Presence”, pertenece al décimo segundo poemario de Raine, al que le da el título. The Presence, que reúne poemas escritos entre 1984 y 1987, fue publicado con el aval editorial de Golgonooza Press en 1987 y, hasta el momento, no ha recibido más que atención ocasional en círculos críticos, académicos y traductológicos. De hecho, la antología de Alzueta Jesús, en cuyas páginas aparece una versión bilingüe del poema, toma como referencia los poemas reunidos en The Collected Poems of Kathleen Raine (2000) y no de los poemarios individuales de Raine. Así, la selección del antólogo opera a partir de una ejecución previa realizada por el editor Brian Keeble con intervención de la poeta. Según 
advierte Alzueta Jesús, docente del área de lenguas extranjeras de la Escuela Oficial de Idiomas de Motril, la antología "no ha buscado representar de manera exhaustiva los distintos temas y voces de nuestra poeta sino ahondar en su voz más característica” (ALZUETA JESÚS, 2006, p. 14). Esta declaración, que pone en el lugar de experto al antólogo y el traductor, resulta al menos problemática para la concreción de los objetivos que en su interior se proponen. La antología de poemas escogidos se inscribe como una de las publicaciones de la institución mencionada, un centro educativo para personas adultas situado en Granada ${ }^{7}$. Se trata, efectivamente, de una obra que se ofrece al público como una entre otras actividades culturales que fundamentan la filosofía educativa del centro en cuestión. En otras palabras, la identificación de esa "voz más característica", aun cuando el antólogo no dé cuenta explícita de ello, está atravesada por la misión educativa que distingue a esta institución y a cuyos valores la antología debe, en teoría, ajustarse.

Respecto de los principios que regulan la traducción, Alzueta Jesús señala que ha buscado ser "fiel al espíritu antes que a la forma" (2006, p.14), para lo cual, en ocasiones, ha debido dar lugar a su propia voz en la traducción. Esta intervención debe entenderse, según 114 postula el traductor, como un "injerto necesario para la vida del nuevo árbol”. La metáfora, sin dudas, resulta de interés para comprender la noción de traducción que sostiene el trabajo de Alzueta Jesús. Los injertos, como sabemos, muchas veces favorecen la propagación artificial de una especie que encuentra cierta dificultad para su crecimiento en un medio que no le es propio. Así, la metáfora postula una relación orgánico-dependiente entre la obra y su traducción, la cual queda señalada en la antología a través de su presentación bilingüe.

En el ámbito francófono, el poema ha sido recibido a través de una traducción que, prácticamente desprovista de signos paratextuales, revela una conciencia integradora en tanto transpone el poemario en su conjunto. Cabe señalar que este no es un caso aislado; en general, la traducción al francés de la obra poética, crítica y autobiográfica de Raine ha sido regida por esta misma política de traducción. La editorial independiente Verdier, especializada en la difusión de textos literarios, filosóficos, religiosos y artísticos, avala esta publicación ${ }^{8}$. En cuanto a su presentación, la versión bilingüe, tanto en la edición española como en la francesa, registra el carácter documental de las obras. Esta condición habilita una lectura que, potencialmente, pone en relación los textos fuente y meta y visibiliza así, de manera cabal, el hecho mismo de la traducción. Indudablemente, esta es una tendencia muy habitual en las publicaciones actuales, la cual es especialmente valorada por los lectores bilingües (BOASEBEIER, 2009), tanto en los circuitos literarios y académicos como en los comerciales. 
¿Cómo se imposta una voz como la de Raine en español? ¿Cómo se escucha la cadencia de una voz singularizada y fragmentada? ¿Cómo se da cuerpo en otra lengua a aquello que, aun sin poder nombrarlo, sabemos que domina el poema? Para Raine (1957), el poema, que se estructura en torno a una poderosa idea que le da sustancia, solo se articula a través de su aprehensión poética. La tarea del poeta, como indica Keeble (2016), se orienta en Raine hacia al centro sagrado de la experiencia humana y no es jamás la descripción de una experiencia individual.

A lo largo de sus dieciocho líneas escritas en verso libre, "The Presence" pone en escena un concierto de sensaciones y reminiscencias que se inscriben en los imbricados laberintos de la existencia, la eternidad y la espiritualidad ${ }^{9}$. En el poema, así como en otros fragmentos del poemario The Presence y de su obra en general, Raine ofrece una articulada red de sentidos en torno a la condición, la circunstancia y la posibilidad de una presencia que armoniza en unos mismos acordes la poesía, la mortalidad, la naturaleza, lo sagrado ${ }^{10}$. Como indica Keeble (2016), el poema se relaciona con otros pasajes de la obra de Raine en los que el yo queda disperso entre la naturaleza y la memoria y se postula como conocedor de una realidad trascendente que deviene una muestra de una unidad compartida, que alcanza a todos.

En términos generales, el análisis de los procedimientos y técnicas de traducción empleadas en los poemas nos permite constatar que la reinscripción del sentido poético evidente en la versión en español implica un alto grado de racionalización. La racionalización, entendida, siguiendo a Antoine Berman (1984), como una de las fuerzas o tendencias que dominan el quehacer del traductor, alude a la recomposición estructural del texto fuente en la traducción. Esta tendencia, que afecta, entre otros, los planos de la sintaxis, la puntuación y el nivel gráfico, produce un doble efecto en la versión española. Los procedimientos orientados a la racionalización confieren un mayor grado de abstracción y, asimismo, aportan a la determinación de referencias y géneros no explicitados en la primera versión del poema. Tal como intentaremos mostrar, este mayor grado de racionalización conlleva un menor grado de eficacia poética que el alcanzado en las versiones inglesa y francesa.

El régimen de forma del poema "The Presence" es acogido de manera diversa en las versiones estudiadas. En relación con su estructura general, la traducción española manifiesta la reorganización del material a través de la adición de un espacio entre los versos séptimo y octavo, lo cual determina la existencia de dos estrofas. La configuración de un nuevo espacio poético contribuye a la introducción de una suerte de segundo paso y conclusión en la enunciación poética. Asimismo, se observa que el número de versos solo se mantiene en la 
versión francesa, que conserva una composición de dieciocho versos, mientras que la española, por su parte, reajusta también su ordenamiento sintáctico y tiene diecisiete.

La racionalización del poema también se incrementa en el nivel gráfico. En inglés, es típico, aunque no obligatorio, que la primera palabra de cada verso de un poema aparezca escrita con mayúscula inicial. Ante este ademán de la palabra poética, que acentúa los quiebres sintácticos, la versión francesa del poema preserva sus rasgos gráficos, los cuales, por otra parte, son afines a su dicción más tradicional. La versión en español se ajusta al mandato de la lengua receptora y, al hacerlo, aporta fluidez racionalizadora a la enunciación. La pausa enunciativa que produce la separación en estrofas se ve reforzada en el interior del poema a través de ciertos procedimientos como la introducción de cláusulas parentéticas, señaladas mediante rayas en los versos sexto y último, que imponen un nuevo ritmo y, consecuentemente, un nuevo sentido para el poema: “- cuán clara entre las hojas verdes y fragantes -”, “- sin saber lo que dice -, esa voz inmortal".

En el ámbito de la articulación léxico-semántica, se distingue en español el empleo de sustantivos que evocan entidades más abstractas, menos concretas que las definidas en el texto 116 fuente. Al igual que los procedimientos descriptos en los planos sintáctico y gráfico, esta articulación intensifica el carácter más abstracto de la presencia que se desliza en el poema. En este sentido, el comienzo del poema es destacable. Tanto el poema en inglés como la versión francesa se inician con la mención de una cualidad mediante los adjetivos "present" y “présente”, respectivamente. El adjetivo modifica el sustantivo "presence” / "présence”, el cual, muy significativamente, queda ubicado a la postre del primer verso. Se pone de relieve así la paronimia entre "presence" y "present" a través de la yuxtaposición de significantes y significados, sonido y sentido, cristalizados en distintas categorías gramaticales. La repetición, por otra parte, establece una continuidad de sentido, tanto en inglés como en francés: "Present, ever-present presence"; "Présente, eternellement présente présence".

En el poema en español, en cambio, opera un reordenamiento que altera las redes semánticas y temáticas internas del poema. Como resulta evidente, esta tendencia a la racionalización no se plantea como una restricción de la lengua receptora sino como una opción de la traducción. La modificación de la sintaxis y el aporte de una mayor concisión de significantes implica aquí la reducción en extensión del verso primero que ahora se enlaza con el segundo en español: "Presencia siempre viva, nunca has dejado de estar". La fatalidad de la existencia "Never have you not been", dirimida entre "ser" y “estar" en español, se cobra aquí la polisemia del verbo y reorienta el sentido. En francés, en cambio, la polivalencia del verbo 
"être" habilita nuevamente la posibilidad de la significación y de su aprehensión: "Jamais tu n'as cessé d'être". La permanencia en el devenir queda aquí magistralmente aludida a través de las marcas de negación dobles que acompañan el presente perfecto, repuestas en francés, pero no en español.

Estos procedimientos se constatan, cabe mencionar, en otros pasajes del poema. Así, en la versión española del verso octavo (“As in childhood always new, anew”.) se altera la relación semántica y sonora que media entre "always new, anew": "como en la infancia, siempre nueva y otra”. El francés recupera la sonoridad a través de la expresión más creativa: “toujour nouveau, de nouveau". Asimismo, se advierte una conciencia más fuerte y restrictiva sobre la puntuación, ausente en el texto fuente y en la versión francesa, que define en español el sustantivo "infancia" y determina, junto con la adición del género ("como en la infancia, siempre nueva y otra"), una referencia para la introducción de ese otro, no presente en el original, y ahora ligado en la traducción a la infancia ineludiblemente. En francés, en cambio, y siguiendo el estilo más propio de Raine, se prescinde oportunamente de la puntuación instaurando la posibilidad de distintos niveles de lectura para el poema: "Comme au temps de l'enfance toujours nouveau, de nouveau".

Más aún, la racionalización imprime en esta versión un orden normalizador. En el tercer verso de las versiones en inglés y francés (segundo verso en español), el recurso de la repetición adquiere un nuevo sentido. En efecto, a través de la reiteración de los adverbios "here" y "now" se profundiza la continuidad de una presencia, que situada en el "aquí y ahora", busca trascender en el devenir. En la segunda aparición de los adverbios se invierte el orden sintáctico habitual de la enumeración expresada en la colocación "here and now": "Here and now in every now and here" (nuestro énfasis). Esta inversión, que transgrede lo establecido por los usos más habituales del inglés, aparece recreada en la versión francesa, "Ici et maintenant en chaque maintenant et ici”, pero se pierde en la traducción española, la cual mantiene el orden de la colocación más usual del español, sin permitir que el orden marcado del poema original atraviese su fibra: “Aquí y ahora en cada aquí y ahora”.

La semántica más abstracta de la versión española se evidencia también en ciertos procedimientos como el reemplazo de sustantivos plurales por sustantivos singulares que indican una naturaleza más inconmensurable. Así, la traducción al español del sexto verso (quinto de la versión española), recupera el sustantivo "aroma" para verter el sentido de "scents": "Of scents, of notes, the evening blackbird's song"; “de aroma y música, la canción del mirlo". Ciertamente, "aroma" evoca la noción de un perfume agradable comprendido ahora 
en su abstracción y no en la multiplicidad diversa habilitada en el poema a través del plural. Por su parte, la versión francesa sigue a su antecesora en lo que respecta a la enumeración, el número de los sustantivos del original y la puntuación, todas ellas marcas de la dinámica interna del decir poético: "De senteurs, de notes, le chant du merle dans le soir". A través del mismo procedimiento, en la versión española, la "música" toma el lugar de las notas ("notes"), las cuales, por su descripción semántica y número plural, indican la posibilidad de una pluralidad de voces. La unión de dos frases preposicionales desplaza nuevamente la repetición de la dicción del texto fuente. Así, a través de la adición de la conjunción copulativa “y”, las frases "Of scents, of notes" se transforman en una suerte de unidad: "aroma y música". Este sintagma nominal compuesto imprime un nuevo ritmo de expresión al poema. La polisemia del texto fuente se ve aquietada en ese mismo verso en la traducción al español, en el que la referencia temporal "evening” desaparece. La polivalencia de este atardecer, que alude principalmente al canto del mirlo, contribuye a la inscripción de esta presencia en un momento particular del día y, por analogía, de la vida, que remite al atardecer y a la vejez. En este caso, el matiz de sentido evocado también se diluye en francés a través de la explicitación adverbial al final del verso 118 (“dans le soir”).

La mención del mirlo vespertino prepara el camino para la introducción de un nuevo sentido en el verso noveno. A través de una metonimia, la imagen de la poeta queda aludida a través de la mención de su mano que escribe y envejece: "My hand that writes is ageing, but I too". En español, la cláusula determinante desaparece, lo cual provoca una pérdida del sentido fundamental implicado en la tarea creativa de la escritura: "Esta mano envejece, pero también repito". La versión francesa, en cambio, habilita los dos sentidos en su interior: "Ma main qui écrit viellit, mais moi aussi".

Conviene comentar también el cambio de perspectiva evidente en los últimos versos del poema en la versión española. En la traducción de los dos últimos versos del poema, "I, living, utter as the blackbird/ In ignorance of what it tells, the undying voice", la agentividad se ve afectada por un desplazamiento significativo. La música surge aquí, brota, del yo que enuncia el poema: "Brota viva de mí, como del mirlo / - sin saber lo que dice -, esa voz inmortal”, sin que ello suponga una acción deliberada como queda establecido a través del enunciado: "I, living, utter". La identificación más directa entre el yo y el mirlo, que se presenta como una imagen que vincula también el yo, la poesía y la naturaleza, se desvanece parcialmente en el poema en español a través del cambio de sujeto, la puntuación y el término de comparación. Del mismo modo que el mirlo no puede evitar su canto, el poeta debe decir su palabra, incluso 
cuando el sentido de esa palabra le sea todavía desconocido. La simpleza de esta sentencia comprende, sin dudas, una afirmación respecto del métier del poeta y de la poesía. La versión francesa busca una reconfiguración del decir que sigue más la letra de su origen: "Moi, vivante, comme le merle je fais entendre/ Dans l'ignorance de ce qu'elle dit, la voix qui ne meurt pas".

\section{Conclusiones}

A través de la reseña de publicaciones presentada, se ha constatado que la presencia de la voz poética de Raine en el ámbito del español se limita a un número modesto de traducciones, incluidas generalmente en antologías y selecciones de poemas, publicadas en revistas especializadas. A toda selección, así como a toda antología subyacen, necesariamente, los criterios que aglutinan sus partes para asegurar una cierta coherencia interna. Como indica Frank (1998), la relación entre los fragmentos seleccionados y aquellos que han sido desestimados resulta crucial para comprender los principios que orientan la labor de los antólogos.

El caso de estudio, centrado en el análisis pormenorizado de "The Presence" en relación con su aparición dentro del poemario The Presence (RAINE, 1987) y sus posteriores versiones en español y francés, nos permite arribar a las siguientes conclusiones. En español, el poema es parte de la antología Fragmentos de una visión sagrada, la cual se revela como un intento de representar los temas que distinguen la voz más singular de la poeta británica. La antología y su traducción a cargo de Alzueta Jesús están condicionadas por la reinscripción institucional que pretende su ejecución. La voz de Raine en español se inserta en un contexto institucional educativo en el que es presentada como un producto cultural. Más allá del criterio aglutinante que fundamenta esta antología, prevalece, no obstante, la fragmentariedad inherente a toda selección. La selección de los poemas, considerada como una de las estrategias que regulan una traducción, condiciona las técnicas que luego se aplican para la traducción efectiva de los poemas. En otras palabras, el reordenamiento de la producción de Raine en la antología no solo se materializa en términos macro o globales, sino que también se vuelve evidente en el nivel del microanálisis de los poemas traducidos. La propia naturaleza de la selección hace que en la traducción se privilegien técnicas que dan cuenta de la singularidad antes que del ensamble orgánico que constituye la voz de la poeta británica, la cual parecería ser aprehensible solo en el conjunto de su existencia. En la traducción al español de los poemas, marcados por una fuerte tendencia a la racionalización y la abstracción, no se recuperan satisfactoriamente los marcos 
discursivos, conceptuales y estéticos que singularizan la simpleza profunda de la poética de Raine.

En contraposición, la versión francesa del poema, "La Présence”, inserta en el poemario completo de Raine, La Présence, a cargo de Philippe Giraudon, reviste mayor organicidad y sensibilidad poéticas. Precisamente, el examen de esta traducción nos ha permitido evaluar la materialización distinta de la voz de Raine en un contexto de enunciación en el que la relación entre la parte seleccionada y el todo, al que esa parte pertenece, no ha sido afectada por la tarea del antólogo o del traductor. La reinscripción del sentido se orquesta aquí de manera armónica en un espacio editorial e institucional que promueve la complejidad de la palabra poética desde su fundación. El análisis comparativo de los poemas confirma nuestra hipótesis respecto del carácter fragmentario de la composición en español. La versión francesa restituye con mayor acierto el sentido y forma del texto fuente e intenta, como propone Antoine Berman (1999), evocar un trabajo sobre la letra, capaz de modificar incluso la lengua de la traducción. Se trata, como indica Delfina Muschietti (2013), de una literalidad productiva. El francés aparece aquí como una lengua más hospitalaria, que se transforma en una relación interlingüística y cultural

120 que genera nuevos sentidos en la traducción. Resulta, en este sentido, una traducción más innovadora y eficaz que la de Alzueta Jesús, la cual se ajusta más a las locuciones y expresiones establecidas en el español. En el futuro, será de interés cotejar los resultados obtenidos a la luz de otras investigaciones que aborden el modo en que se reinscriben otros pasajes de la obra de Raine en nuevos espacios lingüísticos, literarios y culturales a través de la traducción.

\section{REFERENCIAS}

ALONSO, D. (ed.). Antología de poetas ingleses modernos. Madrid: Gredos, 1963.

BENEDICT, B. M. The Paradox of the Anthology: Collecting and Difference in EighteenthCentury Britain, New Literary History, v. 34, n 2, p. 231-256, 2003.

BERMAN, A. L'épreuve de l'étranger. Culture et traduction dans l'Allemagne romantique. París: Gallimard, 1984.

BERMAN, A. La traduction et la lettre ou l'Auberge du lointain. París: Seuil, 1999.

BOASE-BEIER, J. 2009. Poetry. En: BAKER, M.; SALDANHA, G. (ed.). Routledge Encyclopedia of Translation Studies, 2 ed. Londres y Nueva York: Routledge, 2009. p. 194197. 
BOASE-BEIER, J. "Poetry Translation". En: MILLAN, C.; BARTRINA, F. (ed.). The Routledge Handbook of Translation Studies. Londres y Nueva York: Routledge, 2013. p. 475-487.

BORGES, J. L. Las dos maneras de traducir. En: Textos recobrados 1919-1930. Buenos Aires: Emecé, [1926] 1997. p. 256-259.

CIPLIJAUSKAITÉ, B. et al. Voces femeninas de Occidente. El Ciervo, v. 40 (487), p. 21-24, 1991.

CLARO, A. Las vasijas quebradas. Cuatro variaciones sobre la 'tarea del traductor'. Santiago: Ediciones Universidad Diego Portales, 2012.

EAGLETON, T. How to Read a Poem. Oxford: Blackwell, 2007.

EL-SHAER, M. S. Mysticism in the poetry of Kathleen Raine. Durham University, 2000. Disponible en: <http://etheses.dur.ac.uk/1687/> Acceso: 15 ago. 2015.

FOSTER, T.C. How to Read Poetry Like a Professor: A Quippy and Sonorous Guide to Verse. Nueva York: Harper Perennial, 2018.

FRANK, A. P. Anthologies of translation. En: BAKER, M.; MALMKJÆR K. (ed.) Routledge Encyclopedia of Translation Studies. Nueva York y Londres: Routledge, 1998. p. 14-16.

FURNISS, T.; BATH, M. Reading Poetry: An Introduction. 2 ed. Londres: Longman, 2007.

HIRSCH, E. How to Read a Poem: And Fall in Love with Poetry. San Diego, Nueva York, Londres: Harcourt, Inc., 1999.

HOLMES, J. Translated! Papers on Literary Translation and Translation Studies. Ámsterdam: Rodopi, 1994.

HONIG, E. (ed.). The Poet's Other Voice: Conversations on Literary Translation. Amherst: University of Massachusetts Press, 1985.

JAKOBSON, R. En torno a los aspectos lingüísticos de la traducción. En: Ensayos de lingüística general. Barcelona: Editorial Seix Barral S. A., [1959] 1981. p. 67-77.

KEEBLE, B. Who Speaks from the Dust?: Kathleen Raine and the Vocation of Poetry. Sewanee Review, v. 124, n 1, p. 117-130, 2016.

LINDOP, G. Kathleen Raine. En: SCOTT KASTAN, D. (ed.). The Oxford Encyclopedia of British Literature, Oxford: Oxford University Press, 2006. v. 1, p. 311-314.

MONTEZANTI, M. Á. Poesía, Arte y Naturaleza en Kathleen Raine. Gramma, v. XXIV (51), pp. 11-24, 2013. 
MUSCHIETTI, D. Poesía y traducción: constelaciones teóricas y traducciones comparadas. En: MUSCHIETTI, D. (comp., ed.). Traducir poesía, la tarea de repetir en otra lengua. Buenos Aires: Bajo la luna, 2013. p. 7-113.

PATERSON, D. Orpheus: A version of Rilke's Die Sonette an Orpheus. Londres: Faber and Faber, 2006.

RAINE, K. Poemas. Traducción: M. Manent. Madrid: Adonáis, Ediciones Rialp, 1951.

RAINE, K. Defending Ancient Springs. Oxford: Oxford University Press, 1957.

RAINE, K. On a Deserted Shore. Dublín; Londres: The Dolmen Press/ Hamish Hamilton, 1973.

RAINE, K. En una desierta orilla. Edición bilingüe. Prólogo, traducción y notas: R. Martínez Nadal. Madrid: Ediciones Hiperión, [1973] 1981.

RAINE, K. The Presence: Poems, 1984-87. Londres: Golgonooza Press, 1987.

RAINE, K. Virginia Woolf at Girton. En: STAPE, J. H. (ed.). Virginia Woolf. Macmillan Interviews and Recollections. Londres: Palgrave Macmillan,1995.

122 RAINE, K. Baedeker poético: Kathleen Raine. Traducción: PEÑALVER, S. et al. Dactilo. Revista del aula de poesía, v 2, p. 21-38, 1999.

RAINE, K. Collected Poems. Edited by B. Keeble. Londres: Golgonooza Press, 2000.

RAINE, K. La Présence. Poèmes 1984-1987. Traducción: P. Giraudon. Lagrasse: Verdier, 2003.

RAINE, K. Adamar. Revista de Creación. Introducción y traducción: C. Janés. (200-2004) Disponible: http://www.adamar.org/archivo/ii_epoca/num14/v2.html. Acceso: 20 jul. 2018.

RAINE, K. Fragmentos de una visión sagrada. Traducción e introducción: E. Alzueta Jesús. Prólogo: José Lupiánez. Motril, España: Editorial Aljamía, 2006.

RAINE, K. Poesía y Naturaleza. Kathleen Raine. Antología bilingüe. Selección traducción y notas: A. Gómez Tomé. Murcia: Ediciones Tres Fronteras, 2008.

RAINE, K. Kathleen Raine: durmiendo bajo una espina. Selección, traducción y notas: M. Á. Montezanti. Hablar de poesía, v. 36, 2017.

RUDMAN, M. Kathleen Raine's Originality. New England Review. v.23, n.2, p.123-125, 2002.

SHERRARD, P. Kathleen Raine and the Symbolic Art. Temenos Academy Review, v. 11, p. 180-208, 2008. Disponible en: https://www.temenosacademy.org/PHILIP\%20SHERRARD\%20Kathleen\%20Raine\%20and $\% 20$ the $\% 20$ Symbolic\%20Art.pdf. Acceso: 10 sep. 2018. 
VENUTI, L. The Poet's Version; or, An Ethics of Translation. Translation Studies, v. 4, n 2, p. 230-247, 2011.

WOLOSKY, S. The Art of Poetry. How to Read a Poem. Oxford: Oxford University Press, 2000 .

\section{Apéndice}

\section{The Presence}

Present, ever-present presence,

Never have you not been

Here and now in every now and here,

And still you bring

From your treasury of colour, of light,

Of scents, of notes, the evening blackbird's song,

How clear among the green and fragrant leaves,

As in childhood always new, anew.

My hand that writes is ageing, but I too

Repeat only and again

The one human song, from memory

Of a joy, a mode

Not I but the music knows

That forms, informs us, utters with our voices

Concord of heaven and earth, of high and low, who are

That music of the spheres Pythagoras heard.

I, living, utter as the blackbird

In ignorance of what it tells, the undying voice.

Kathleen Raine ([1987] 2003, p. 50)

\section{La presencia}

Presencia siempre viva, nunca has dejado de estar aquí y ahora en cada aquí y ahora;

y todavía me traes

de tu tesoro de color, de luz,

de aroma y música, la canción del mirlo,

—cuán clara entre las hojas verdes y fragantes-

como en la infancia, siempre nueva y otra.

Esta mano envejece, pero también repito

una vez y otra vez

la única canción humana, ese recuerdo

de la alegría, un modo

que no yo, mas la música, conoce que

nos forma e informa y con nuestra voz dice

la concordia del cielo y de la tierra,

música de los astros que escuchase Pitágoras.

Brota viva de mí, como del mirlo,

— sin saber lo que dice—, esa voz inmortal.

Traducción: Emilio Alzueta Jesús (2006, p. 77)

\section{La Présence}

Présente, éternellement présente présence,

Jamais tu n'as cessé d'être 
Ici et maintenant en chaque maintenant et ici,

Et tu apportes encore

De ton trésor de couleur, de lumière,

De senteurs, de notes, le chant du merle dans le soir,

Si clair parmi les feuilles vertes et odorantes,

Comme au temps de l'enfance toujours nouveau, de nouveau.

Ma main qui écrit vieillit, mais moi aussi

Je répète uniquement et encore une fois

L'unique chant humain, du fond du souvenir

D'une joie, un mode

Que non moi mais la musique connaît

Qui nous forme, nous informe, fait entendre par nos voix

L'accord du ciel et de la terre, d'en haut et d'en bas, qui sont

Cette musique des sphères que Pythagore perçut.

Moi, vivante, comme le merle je fais entendre

Dans l'ignorance de ce qu'elle dit, la voix qui ne meurt pas.

Traducción: Philippe Giraudon ([1987] 2003, p. 51)

\begin{abstract}
${ }^{1}$ Este trabajo corresponde a nuestras tareas como integrante del proyecto "Kathleen Raine. Relectura creativa de la tradición lírica en lengua inglesa", dirigido por el Dr. Miguel Á. Montezanti y codirigido por la Dra. Anahí Mallol (PID, Universidad Nacional de La Plata, Argentina, H605).

${ }^{2}$ María Laura SPOTURNO es doctora en letras por la Universidad Nacional de La Plata (UNLP). Se desempeña como profesora adjunta de Traducción Literaria 1 y de Literatura de los EEUU (FaHCE, UNLP). Es investigadora del Consejo Nacional de Investigaciones Científicas y Técnicas (Argentina) y directora del proyecto "Escrituras 124 de minorías, ethos y (auto) traducción" (PID, UNLP, 2017-2020). En la actualidad, su investigación aborda el problema de la subjetividad en relación con diversas prácticas de traducción, autotraducción y retraducción así como el examen de la relación entre traducción, género y feminismos.
\end{abstract}

Consejo Nacional de Investigaciones Científicas y Técnicas, Argentina. Universidad de la Plata, Argentina. Buenos Aires, Argentina.

ORCID: https://orcid.org/0000-0002-9678-5767

Email: lauraspoturno@gmail.com

Página personal: https://www.conicet.gov.ar/new_scp/detalle.php?id=29560\&datos_academicos=yes

${ }^{3}$ Los poemas completos aparecen transcriptos en el Apéndice de este artículo.

${ }^{4}$ Se trata de reflexiones que pueden resultar de interés para la didáctica de la traducción poética.

${ }^{5}$ Las metáforas corresponden a Eagleton (2007) y Montezanti (2013) respectivamente.

${ }^{6}$ Para una introducción general a la obra de Raine, podrá consultarse, entre otros, Lindop (2006), Montezanti (2013, 2017). Sherrard (2008) es iluminador respecto de la poesía, la filosofía y el arte de Raine; y Keeble (2016), respecto de la concepción de creación y poesía de Raine.

${ }^{7}$ Para mayor información, consultar: http://www.eoimotril.org/trayectoria/.

${ }^{8}$ Para mayor información, consultar: https://editions-verdier.fr.

${ }^{9}$ El poema apareció también en un apéndice de una tesis de doctorado (EL-SHAER, 1987). A su publicación en The Presence (1987) le siguió su inclusión en la antología The Collected Poems (RAINE, 2000).

${ }^{10}$ Para ampliar este tema, ver, entre otros, El-Shaer (1987), que incluye además otros poemas no publicados como "A small matter" (351) y "Confrontation" (361), que resultan significativos para ponderar el sentido de "The Presence". 